\title{
RESISTOTYPING OF STAPHYLOCOCCUS AUREUS
}

\author{
S. D. Elek and Caroline Moryson \\ Department of Medical Microbiology, St George's Hospital Medical School, \\ London $S W 1$
}

THE principle of resistotyping, i.e., the differentiation of bacterial strains by the degree of their resistance to selected chemical substances, was first described by Elek and Higney in 1970 . Their method of resistotyping strains of Escherichia coli from cases of urinary-tract infection gave results that were in good agreement with those of serotyping. A similar system was worked out for Shigella sonnei (Elek, Davis and Miles, 1973) and the resistotypes agreed well with the colicine types and with the epidemiological findings in various outbreaks. The present work is an attempt to assess the value of resistotyping of Staphylococcus aureus, for which there is already a longestablished epidemiological tool in the form of phage typing.

\section{MATERIALS AND METHODS}

Staphylococci. Originally 16 strains of $S$. aureus taken at random were examined in detail to establish a resistotyping system; 12 of these were finally selected as reference strains for the method. Another 301 strains, selected from various incidents of staphylococcal disease in hospitals, were used to evaluate the system.

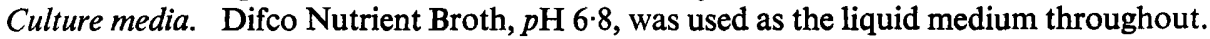
The solid medium employed was Difco Antibiotic Medium No. 2, made up in tris-buffer (Tris hydroxymethyl) methylamine, $\mathrm{BDH} 27119$ at $p \mathrm{H} 7 \cdot 6$. The concentration used was $10 \%$ higher than that recommended by the manufacturers to allow for the dilution consequent upon the addition of the chemical marker.

Screening of antibacterial compounds. We tested 334 randomly chosen chemicals by the gradient-plate method in the manner already described (Elek and Higney, 1970). They included a variety of organic and inorganic compounds and some dyes. Selective toxicity for $S$. aureus was revealed by 90 chemicals. These were further tested in plates containing a series of fixed concentrations of the compounds around that which appeared to show selective toxicity in the gradient plate (see Elek et al., 1973). The plates were seeded with suspensions of the reference strains by means of a multiple-inoculating machine. The inoculum size was adjusted to contain approximately $6 \times 10^{3}$ organisms. After this step only 12 of the 90 compounds remained that showed sufficient discrimination to form the basis of a resistotyping system.

Chemicals used for resistotyping. The compounds chosen, together with their working concentrations are shown in table I. The chemicals are referred to by capital letters of the alphabet: D, F, H, I and L were obtained from British Drug Houses Chemicals Ltd, Poole, Dorset, in Analar grade; A, C, J, and K were supplied by the same firm in the form of " Laboratory grade " reagents; B was supplied by Edward Gurr Ltd, 42 Upper Richmond Road, London SW14; E was obtained from Kodak Ltd, Kirkby, Liverpool L33 7UF. Our batch of chemical G came originally from ICI Ltd, Pharmaceuticals Division, Alderley Park, Macclesfield, Cheshire. It is no longer available from them, but can be supplied by Ralph N. Emmanuel Ltd, 264 Water Road, Wembley, Middlesex. Most of the chemicals

Received 9 July 1973; accepted 15 Sept. 1973.

J. MED. MICROBIOL.- VOL. 7 (1974) 
could be dissolved directly in distilled water in the concentrations indicated for the mastersolutions (table I). Chemicals A and B were first dissolved in $2 \mathrm{ml}$ of absolute ethyl alcohol and then further diluted with distilled water. Chemical $\mathrm{G}$ was dissolved in $1 \mathrm{ml}$ of alcohol and then diluted to the concentration of the master solution. Chemical $\mathrm{K}$ was dissolved in $15 \mathrm{ml}$ of alcohol initially. All the master solutions so obtained were stored at $4{ }^{\circ} \mathrm{C}$ and remained stable for at least 2 weeks.

Biological titration. In practice it was not possible to rely on the concentrations obtained by weighing out the chemicals because the range of selective toxicity is extremely fine, and a biological titration was necessary each time a fresh master solution was made. This was performed exactly in the manner previously described (Elek et al., 1973), except that chemical E required $0 \cdot 1-\mathrm{ml}$ steps, whereas the other chemicals could be used in $0 \cdot 2-\mathrm{ml}$ steps.

TABLE I

Compounds chosen for resistotyping Staphylococcus aureus

\begin{tabular}{|c|c|c|c|}
\hline \multirow{2}{*}{$\begin{array}{c}\text { Reference } \\
\text { letter }\end{array}$} & \multirow[b]{2}{*}{ Compound } & \multicolumn{2}{|c|}{ Concentration $(\%)$} \\
\hline & & master solution & working solution* \\
\hline $\begin{array}{l}\text { A } \\
\text { B } \\
\text { C } \\
\text { D } \\
\text { E } \\
\text { F } \\
\text { G } \\
\text { H } \\
\text { I } \\
\text { J } \\
\text { K } \\
\text { L }\end{array}$ & $\begin{array}{l}\text { Phenyl-mercury acetate } \\
\text { Basic fuchsin } \\
\text { Acriflavine } \\
\text { Potassium metabisulphite } \\
\text { Lauryltrimethylammonium bromide } \\
\text { Boric acid } \\
\text { 4-Cyanophenol } \\
\text { Cadmium acetate } \\
\text { Lead nitrate } \\
\text { Cetylpyridinium chloride } \\
\text { 3-Aminophenol } \\
\text { Sodium arsenate }\end{array}$ & $\begin{array}{l}0 \cdot 0001 \\
0 \cdot 01 \\
0 \cdot 24 \\
1 \cdot 0 \\
0 \cdot 007 \\
2 \cdot 75 \\
0 \cdot 5 \\
0 \cdot 4 \\
1 \cdot 62 \\
0 \cdot 01 \\
3 \cdot 6 \\
1 \cdot 2\end{array}$ & $\begin{array}{l}0 \cdot 00007 \\
0 \cdot 0014 \\
0 \cdot 024 \\
1 \cdot 0 \\
0 \cdot 007 \\
2 \cdot 75 \\
0 \cdot 5 \\
0.04 \\
1 \cdot 62 \\
0.002 \\
3 \cdot 6 \\
1 \cdot 2\end{array}$ \\
\hline
\end{tabular}

* Three $\mathrm{ml}$ of working solution is added to $27 \mathrm{ml}$ of nutrient agar.

Technique of resistogram typing. The staphylococci to be tested were grown overnight (for 18 hours) at $37^{\circ} \mathrm{C}$ in $1 \mathrm{ml}$ of broth in bottles. The cultures were placed in a refrigerator at $4^{\circ} \mathrm{C}$ for a short while until required for inoculation. For each chemical, three plates were poured: one at the actual concentration given by the previous biological titration and one plate one step below and one step above this concentration. Whenever possible all strains from one outbreak were tested on the same plate. A single nutrient-agar plate was included as the inoculum control. For the control of the chemicals, the 12 reference strains were tested with every batch of strains. The inoculating machine had 32 inoculating heads and this allowed the testing of 20 strains per batch.

Each glass cup of the inoculating machine received $0.25 \mathrm{ml}$ of sterile distilled water. Before the test, the broth cultures of the strains were transferred from $4{ }^{\circ} \mathrm{C}$ to $37^{\circ} \mathrm{C}$ for $30 \mathrm{~min}$. They were then diluted 1 in 10 with sterile distilled water by adding $9 \mathrm{ml}$ to the $1 \mathrm{ml}$ already in the bottles. A Takatsy loopful $(0.025 \mathrm{ml})$ was transferred from each diluted culture into the appropriate cup of the inoculating machine. These steps resulted in an inoculum size of approximately $6 \times 10^{3}$, which invariably gave confluent growth on the control plate. All 37 plates were then seeded by means of the inoculating machine.

Reading of the resistogram. Table II shows the standard patterns of inhibition of the 12 reference strains. Of the three plates containing the same chemical in slightly different concentrations the one was chosen that gave the closest agreement to the pattern originally found for the reference strains. This plate was then used for reading the results for the rest of the strains. The other two plates were occasionally of value when there was some 
doubt. The resistotype was recorded as the sequence of reference letters (table I) corresponding to the chemicals to which the strain was resistant. Full growth was designated by the letter and absence of growth by a - sign in the place of the letter. Intermediate growth in the form of tiny confluent colonies was indicated by " $f$ " after the letter, and less than full growth by brackets around the letter. Experience showed that, for epidemiological evaluation, partial growth could occasionally be identified either with full growth or with no growth in strains within the same outbreak. This was referred to as a "minor variation ". Thus a strain with resistotype $\mathrm{AB}(\mathrm{C})--\mathrm{FGHI}-\mathrm{K}$ - could be grouped either with strains of resistotype $\mathrm{ABC}--\mathrm{FGHI}-\mathrm{K}-$ or $\mathrm{AB}---\mathrm{FGHI}-\mathrm{K}-$ in an outbreak.

When two organisms showed a major difference in resistance to one or more chemicals (i.e., one organism gave full growth and the other was completely inhibited), the organisms are regarded as different. Thus, $\mathrm{AB}(\mathrm{C})--\mathrm{FGHI}-\mathrm{K}-$ is a different resistotype from $\mathrm{AB}(\mathrm{C}) \mathrm{D}-\mathrm{FGHI}-\mathrm{K}-$.

\section{TABLE II}

Standard resistance patterns and resistotypes of the 12 reference strains

\begin{tabular}{|c|c|c|c|c|c|c|c|c|c|c|c|c|c|}
\hline \multirow{2}{*}{$\begin{array}{l}\text { Strain } \\
\text { number }\end{array}$} & \multicolumn{12}{|c|}{ Resistance pattern* obtained with compound } & \multirow{2}{*}{ Resistotype } \\
\hline & A & B & C & D & E & $\mathbf{F}$ & G & $\mathbf{H}$ & I & $\mathbf{J}$ & $\mathbf{K}$ & L & \\
\hline $\begin{array}{r}1 \\
2 \\
3 \\
4 \\
5 \\
6 \\
7 \\
8 \\
9 \\
10 \\
11 \\
12\end{array}$ & $\begin{array}{l}+ \\
\pm \\
= \\
= \\
= \\
= \\
= \\
\pm \\
+ \\
+ \\
+\end{array}$ & $\begin{array}{c}+ \\
(+) \\
+ \\
+ \\
+ \\
+ \\
+ \\
+ \\
+ \\
+ \\
+ \\
-\end{array}$ & $\begin{array}{l}\bar{z} \\
\bar{t} \\
\bar{t} \\
\bar{z} \\
\bar{z} \\
\bar{t} \\
\bar{z} \\
\overline{-}\end{array}$ & $\begin{array}{l}\bar{z} \\
\bar{z} \\
\overline{-} \\
\overline{-} \\
\bar{z} \\
\bar{t} \\
+ \\
\bar{t} \\
\overline{-}\end{array}$ & $\begin{array}{l} \pm \\
+ \\
\pm \\
\pm \\
\pm \\
\frac{+}{+} \\
\pm \\
-\end{array}$ & $\begin{array}{l} \pm \\
= \\
= \\
\bar{z} \\
= \\
\overline{-} \\
\pm\end{array}$ & $\begin{array}{l}+ \\
+ \\
+ \\
+ \\
+ \\
+ \\
+ \\
+ \\
+ \\
+ \\
+\end{array}$ & $\begin{array}{l}+ \\
+ \\
+ \\
= \\
= \\
= \\
+ \\
+ \\
+ \\
+ \\
+ \\
+\end{array}$ & $\begin{array}{l}+ \\
+ \\
+ \\
= \\
= \\
= \\
+ \\
+ \\
+ \\
+ \\
+\end{array}$ & $\begin{array}{l}\bar{z} \\
\bar{z} \\
\bar{I} \\
\pm \\
\bar{I} \\
\overline{-}\end{array}$ & $\begin{array}{l}+ \\
+ \\
+ \\
+ \\
+ \\
+ \\
+ \\
+ \\
+ \\
+ \\
+ \\
+\end{array}$ & $\begin{array}{l}+ \\
\pm \\
= \\
= \\
= \\
= \\
+ \\
+ \\
(+) \\
+ \\
+ \\
+\end{array}$ & 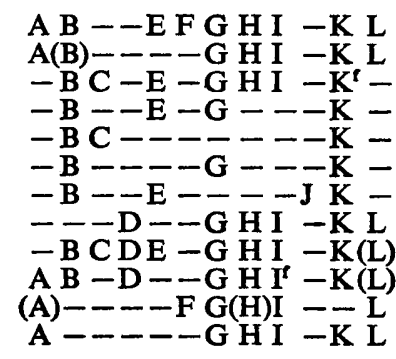 \\
\hline
\end{tabular}

* $+=$ Confluent growth; $(+)=$ growth less than confluent, but more than 10 colonies; $t^{f}=$ fine confluent growth of numerous small colonies; $-=$ no growth.

Glassware. Because of the extreme sensitivity of resistotyping the glassware, screw caps and methods of cleansing were identical to those described by Elek et al. (1973).

Penicillinase production. This was tested for in plates by the iodine-starch technique (Perret, 1954).

Phage typing. This was performed in the Cross-Infection Reference Laboratory by the methods described by Parker (1972). The basic-set phages (Sub-committee on phagetyping of staphylococci, 1967), and certain experimental phages that will be mentioned subsequently, were applied at routine test dilution (RTD) and, when necessary, at 100 times this strength $(\mathrm{RTD} \times 100)$.

\section{RESULTS}

\section{Relationship of resistotype markers to penicillinase plasmids}

Four of the chemicals chosen for resistotyping, mercury (A), cadmium $(\mathrm{H})$, lead (I) and arsenate (L), happened to be metal ions. These metals have been used extensively in genetic studies, and resistances to them are known to be associated with plasmids (Richmond and John, 1964; Novick and Roth, 1968; Peyru, Wexler and Novick, 1969). 
The concentration of these metals for resistotyping was chosen empirically to give the best discrimination between strains. To test whether our resistances were at the same levels as those used in genetic studies we examined 11 strains of $S$. aureus of known genetic constitution, which were kindly provided by Dr Elisabeth Asheshov. These contained various plasmids with known metal markers and also derivatives of these that had lost the plasmids. The findings with mercury, cadmium and lead gave the expected results. A discrepancy was found, however, in the case of arsenate because the concentration used in resistotyping was about twice that employed in the genetic studies.

Relatively little is known about the acquisition of plasmids under natural conditions, but transduction of plasmids is likely to be a rare event in the sense that the relatively small number of strains isolated from an outbreak of limited duration is unlikely to reveal it. Plasmid loss, however, is known to occur with considerable frequency and, because it may alter the observed resistotype, has to be taken into account.

The reversion of penicillin-resistant staphylococci to the sensitive state was observed a long time ago (Barber, 1949) and is now known to be associated with loss of penicillinase plasmids. We encountered plasmid loss during the maintenance of our reference strains when stored on blood agar at $4{ }^{\circ} \mathrm{C}$ and subcultured at intervals of 3 weeks over about 4 years. Penicillinase production was lost by two strains during this time and both strains simultaneously lost their resistances to all four metal markers; one also lost resistance to boric acid, indicating that this marker may similarly be plasmid-borne. A third strain lost resistance to cadmium, lead and arsenate, though it still produced penicillinase. No further studies were made to determine whether this was an instance of chromosomal penicillinase production, whether partial loss occurred from a penicillinase plasmid or whether another plasmid carried the metal resistances.

Penicillinase production was tested for in all 301 of the field strains studied; 27 failed to produce penicillinase and most of these lacked the metal-ion markers. When a strain in a supposedly related group of staphylococci was penicillinase negative, the addition of metal-ion resistances to the resistotype -on the assumption that these had been lost along with the penicillinase plasmid-usually brought it into agreement with the resistotype of the rest of the strains (see Discussion).

\section{Resistotyping of groups of strains from incidents defined by phage typing}

Groups of staphylococci were selected from separate incidents of infection - usually in a single hospital during a limited period of time-in which all the strains in any one group had indistinguishable phage-typing patterns. In all, 224 strains from 27 such incidents were resistotyped.

In nine of the incidents (total 70 strains) the phage-typing patterns and resistotypes gave identical epidemiological information (table III). In four of them the agreement was complete; in the remaining five there were some minor variations in the resistotypes. For two of the strains, which were 
penicillinase negative, it was necessary to add the "lost" metal-ion marker to the resistotype to bring it into conformity with that of the remaining 12 strains.

In seven outbreaks (total 57 strains), most of the resistotypes found were the same within each outbreak, but one strain in each had to be regarded as different from the rest on the basis of the criteria used for resistotyping (table IV). One of these strains on repeating the phage typing gave a different pattern from that obtained in the first test.

TABLE III

Resistotyping of sets of strains from incidents of infection, and with indistinguishable phagetyping patterns; nine incidents in which the results of resistotyping and phage-typing agreed

\begin{tabular}{|c|c|c|c|c|c|}
\hline \multirow[b]{2}{*}{$\begin{array}{l}\text { Incident } \\
\text { number* }\end{array}$} & \multirow{2}{*}{$\begin{array}{l}\text { Number of } \\
\text { strains } \\
\text { examined }\end{array}$} & \multirow[b]{2}{*}{ Resistotype $\dagger$} & \multicolumn{2}{|c|}{ Number of strains } & \multirow[b]{2}{*}{$\begin{array}{l}\text { Phage-typing } \\
\text { pattern§ }\end{array}$} \\
\hline & & & $\begin{array}{l}\text { with minor } \\
\text { variations }\end{array}$ & $\begin{array}{c}\text { penicillinase } \\
\text { negativef }\end{array}$ & \\
\hline $\begin{array}{l}1 \\
2 \\
3 \\
4 \\
5 \\
6 \\
7 \\
8 \\
9\end{array}$ & $\begin{array}{r}14 \\
9 \\
9 \\
8 \\
8 \\
6 \\
6 \\
4 \\
6\end{array}$ & 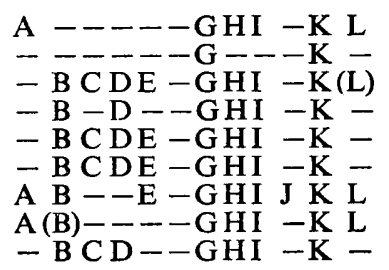 & $\begin{array}{l}1 \\
0 \\
3 \\
3 \\
0 \\
0 \\
0 \\
1 \\
2\end{array}$ & $\begin{array}{l}2 \\
0 \\
0 \\
0 \\
0 \\
0 \\
0 \\
0 \\
0\end{array}$ & $\begin{array}{l}77(88) \\
55 / 71 \\
29 / 52 / 80 / 85 /+ \\
29 / 52 /+ \\
\text { N.T. }(88) \\
29 / 52 / 80 / 85 /+ \\
6 / 54 / 85 /+(88) \\
77 \\
\text { N.T. }\end{array}$ \\
\hline
\end{tabular}

* Each incident occurred in a single hospital during a short period of time; nos. 3, 4 and 6 were in the same hospital at different times.

$\dagger$ See table II.

\# Lost" metal-ion resistance added to pattern.

$\S$ N.T. = Not typable; in parentheses, lysis by experimental phage.

In 11 incidents (total 97 strains) the agreement between phage-typing patterns and resistotypes was less close; table $\mathrm{V}$, showing four of these, illustrates this. Incident no. 1 occurred in a neonatal unit and 10 strains were isolated from babies and staff. Despite the variability of the phage-typing patterns, which made interpretation very difficult, these strains were considered indistinguishable. The resistotypes, however, indicated that all five strains from babies, one strain from a nurse and one from a medical attendant were identical. The remaining three strains from other nurses and staff were different from these. It would seem therefore that resistotyping is capable of grouping together strains of epidemiological importance in cases when the phage pattern leaves some doubt. In incident no. 2 there were nine strains from a burns unit. Although these were indistinguishable by their phagetyping patterns, resistotyping revealed very little homogeneity, and seven different resistotypes were present. It is, of course, accepted that strains with the phage-typing pattern $84 / 85$ include a number of distinct entities that phage typing cannot easily subdivide. In this instance resistotyping appeared 
to do this. The 15 strains in incident no. 3 came from a number of different hospitals in the same area and were lysed only by phage 85 ; in this instance 13 of them proved to be of the same resistotype. Incident no. 4 occurred in the same hospital as incident no. 2, but 3 months later. All 10 strains were lysed

TABLE IV

Resistotyping of sets of strains from incidents of infection, and with indistinguishable phagetyping patterns; seven incidents in which there was almost complete agreement between resistotyping and phage typing

\begin{tabular}{|c|c|c|c|c|}
\hline $\begin{array}{l}\text { Incident } \\
\text { number* }\end{array}$ & $\begin{array}{l}\text { Number of } \\
\text { strains } \\
\text { examined }\end{array}$ & Resistotype $†$ & $\begin{array}{c}\text { Number of } \\
\text { penicillinase- } \\
\text { negative } \\
\text { strains } \ddagger\end{array}$ & $\begin{array}{l}\text { Phage-typing } \\
\text { pattern§ }\end{array}$ \\
\hline \multirow[t]{2}{*}{1} & 8 & $A---E-G H I-K L$ & 1 & \multirow{2}{*}{$\begin{array}{l}84 /+(88) ; 77 / 84+(88) \\
\text { or } 54 / 77 / 84(88) \\
84(88)\end{array}$} \\
\hline & 1 & $A-----G$ HI $-K L$ & 0 & \\
\hline \multirow[t]{2}{*}{2} & 9 & $A(B)-----H I-K L$ & 2 & \multirow{2}{*}{$\begin{array}{l}85 /+(88) ; 85(88 / 90) \\
\text { or N.T.(88/+) } \\
85 /+(88)\end{array}$} \\
\hline & 1 & A B $--E--$ H I J KL & $\mathbf{0}$ & \\
\hline 3 & $\begin{array}{l}9 \\
1\end{array}$ & $\overline{-} \overline{\mathrm{B}}(\overline{\mathrm{C}})-\overline{\mathrm{E}}-\mathrm{G} \mathrm{H}_{\mathrm{H}^{\mathrm{f}} \mathrm{I}}^{\mathrm{H}^{\mathrm{I}}-\mathrm{K}-}$ & $\begin{array}{l}1 \\
0\end{array}$ & $\begin{array}{l}\text { (94) } \\
(94)\end{array}$ \\
\hline 4 & $\begin{array}{l}5 \\
1\end{array}$ & 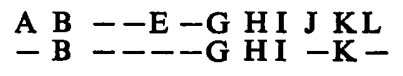 & $\begin{array}{l}0 \\
0\end{array}$ & $\begin{array}{l}29 / 77(88) \\
29 / 77(88) \|\end{array}$ \\
\hline \multirow[t]{2}{*}{5} & 8 & - B CDE-G HI -K- & 0 & \multirow{2}{*}{$\begin{array}{l}29 / 52 / 80 / 85+\text {; or } \\
29 / 52 / 52 \mathrm{~A} / 80 / 85 /+ \\
29 / 52 / 80 /+\end{array}$} \\
\hline & 1 & - B -DE F G(H)I -K- & $\mathbf{0}$ & \\
\hline 6 & $\begin{array}{l}7 \\
1\end{array}$ & 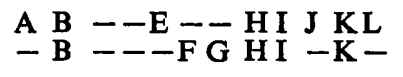 & $\begin{array}{l}0 \\
0\end{array}$ & $\begin{array}{l}85 \\
85\end{array}$ \\
\hline 7 & $\begin{array}{l}4 \\
1\end{array}$ & $\begin{array}{l}\text { A } \\
\text { A B } C-E--\end{array}$ & $\begin{array}{l}\mathbf{0} \\
\mathbf{0}\end{array}$ & $\begin{array}{l}85 \\
85\end{array}$ \\
\hline
\end{tabular}

* Each incident occurred in a single hospital, except no. 3, which included infections in several hospitals in the same region.

$\dagger \ddagger \S$ See table III.

|| A different phage-typing pattern on re-testing.

by phage 85 and only one strain failed to give a reaction with experimental phage 88. Resistotyping indicated the existence of two groups, A-- - $\mathrm{GHI}-\mathrm{KL}$ and $\mathrm{AB}--\mathrm{E}-\mathrm{GHIJKL}$. It is noteworthy, however, that the five strains in the latter of these groups had the same resistotype as three strains in the earlier incident (no. 2) in the same hospital. A third outbreak occurred a few months later in the same hospital in which the phage-typing pattern was also 85 (table IV, incident no. 7), but only one of the five strains isolated on this occasion were of the resistotype most commonly found in the two previous epidemics. All three of these incidents occurred in a burns unit in which phage typing had suggested that a single strain was endemic; the results of resistotyping indicated, however, that several different strains may have been present. 


\section{Use of resistotyping in epidemiological investigations}

In the next phase of the work a direct attempt was made to use resistotyping as a tool in the investigation of epidemics. Seventy-seven strains from six incidents were resistotyped as they were received from the clinical laboratory

TABLE V

Resistotyping of sets of strains from incidents of infection, and with indistinguishable phagetyping patterns; four of the 11 incidents in which resistotyping and phage typing agreed less closely

\begin{tabular}{|c|c|c|c|c|}
\hline $\begin{array}{l}\text { Incident } \\
\text { number* }\end{array}$ & $\begin{array}{l}\text { Number of } \\
\text { strains } \\
\text { examined }\end{array}$ & Resistotype $\dagger$ & $\begin{array}{c}\text { Number of } \\
\text { penicillinase- } \\
\text { negative } \\
\text { strains } \ddagger\end{array}$ & $\begin{array}{l}\text { Phage-typing } \\
\text { pattern§ }\end{array}$ \\
\hline 1 & $\begin{array}{l}2 \\
1\end{array}$ & $\begin{array}{l}-\mathrm{B}-\mathrm{D}--\mathrm{GH} \text { I }-\mathrm{K}- \\
-\mathrm{BCDE}-\mathrm{GH} \text { I }-\mathrm{K}- \\
-\mathrm{BCD}--\mathrm{GH} \mathrm{I}-\mathrm{K}-\end{array}$ & $\begin{array}{l}0 \\
0\end{array}$ & $\begin{array}{l}29 / 52 / 80 / 42 \mathrm{E} /+; \\
29 / 52 / 42 \mathrm{E} / 81 /+; \\
29 / 52 / 52 \mathrm{~A} / 80 / 42 \mathrm{E} /+; \\
29 / 52 / 52 \mathrm{~A} / 79 / 80 / 83 \mathrm{~A} ; \\
29 / 52 / 55 \mathrm{~A} / 80 / 42 \mathrm{E} / 83 \mathrm{~A} / 81 /+ \\
29 / 52 / 52 \mathrm{~A} / 80 /+; \\
29 / 52 / 52 \mathrm{~A} / 80 / 42 \mathrm{E} / 83 \mathrm{~A} / 81 /+ \\
29 / 52 / 80 / 42 \mathrm{E} / 83 \mathrm{~A} / 81 /+\end{array}$ \\
\hline 2 & $\begin{array}{l}3 \\
1 \\
1 \\
1 \\
1 \\
1 \\
1\end{array}$ & 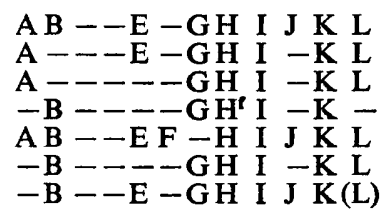 & $\begin{array}{l}1 \\
0 \\
0 \\
0 \\
0 \\
0 \\
0\end{array}$ & $\begin{array}{l}85(88) \\
85(88) \\
85(88) \\
85(88) \\
85 \\
85 \\
85\end{array}$ \\
\hline 3 & $\begin{array}{r}13 \\
1 \\
1\end{array}$ & 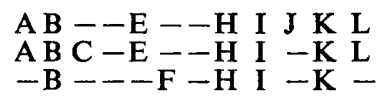 & $\begin{array}{l}2 \\
0 \\
0\end{array}$ & $\begin{array}{l}85 \\
85 \\
85\end{array}$ \\
\hline 4 & $\begin{array}{l}4 \\
5 \\
1\end{array}$ & 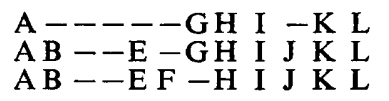 & $\begin{array}{l}2 \\
2 \\
0\end{array}$ & $\begin{array}{l}85 /+(88) \\
85 /+(88) \\
85\end{array}$ \\
\hline
\end{tabular}

* Incidents 2 and 4 occurred in the same hospital respectively in January and April 1972 (incident 7 in table IV followed in August 1972); incident 3 included infections in several hospitals.

$\dagger \ddagger \S$ See table III.

and were not selected in any way. The phage-typing patterns and epidemiological information were obtained later (table VI).

Six strains were isolated in incident no. 1; two of them were the same both by resistotyping and in phage-typing pattern; two others $(-\mathrm{B}-\mathrm{D}--\mathrm{GHI}-\mathrm{K}-$ ) shared the same resistotype, but one was untypable by phages. The remaining two strains were different from each other, and from the rest, both by resistotyping and phage patterns.

Incident no. 2 occurred 2 months later in the nursery of the same hospital. Six of the strains had the same resistotype and phage-typing pattern as the first two strains in the previous incident; thus there was complete agreement between the two methods. 
No. 3 was an outbreak of food poisoning. The resistotype of two strains isolated from the incriminated ham and one from the nose of a food handler

TABLE VI

Results of independent resistotyping and phage typing of staphylococci from six incidents

\begin{tabular}{|c|c|c|c|c|}
\hline $\begin{array}{l}\text { Incident } \\
\text { number* }\end{array}$ & $\begin{array}{l}\text { Number of } \\
\text { strains }\end{array}$ & Resistotype $\dagger$ & $\begin{array}{l}\text { Number of } \\
\text { penicillinase- } \\
\text { negative } \\
\text { strains } \ddagger\end{array}$ & $\begin{array}{l}\text { Phage-typing } \\
\text { pattern§ }\end{array}$ \\
\hline 1 & $\begin{array}{l}2 \\
1 \\
1 \\
1 \\
1\end{array}$ & 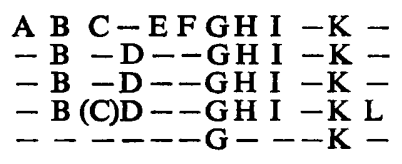 & $\begin{array}{l}0 \\
0 \\
0 \\
0 \\
0\end{array}$ & $\begin{array}{l}\text { 52/52A } / 80 / 81 \\
\text { N.T. } \\
52 / 75 /+ \\
81 /+ \\
71\end{array}$ \\
\hline 2 & $\begin{array}{l}6 \\
1\end{array}$ & A B C - E F GH I $-\mathrm{K}-$ & $\begin{array}{l}0 \\
0\end{array}$ & $\begin{array}{l}52 / 52 \mathrm{~A} / 80 / 81 \| \\
71\end{array}$ \\
\hline 3 & $\begin{array}{l}3 \\
1 \\
1\end{array}$ & $\begin{array}{l}-(\mathrm{B})-\mathrm{D}--\mathrm{GH} \mathbf{I}-\mathrm{K} \mathrm{L} \\
-(\mathrm{B})---\mathrm{GH} \\
--\mathrm{D}--\mathrm{G}-\mathrm{I}-\mathrm{K}=\end{array}$ & $\begin{array}{l}3 \\
0 \\
0\end{array}$ & $\begin{array}{l}6 / 42 \mathrm{E} / 47 / 54 / 81 \\
85 /+ \\
\text { N.T. }\end{array}$ \\
\hline 4 & $\begin{array}{l}2 \\
1 \\
1 \\
6 \\
1\end{array}$ & 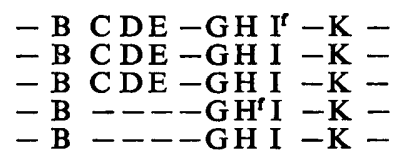 & $\begin{array}{l}2 \\
0 \\
0 \\
0 \\
1\end{array}$ & $\begin{array}{l}(89 / 90) \\
29 / 77 / 84 /+ \\
29 / 52 / 79 / 80 / 77 / 84 / 85 /+ \\
53 / 83 \mathrm{~A} \\
\text { N.T. }\end{array}$ \\
\hline 5 & $\begin{array}{l}4 \\
1 \\
4 \\
1 \\
1 \\
2 \\
1\end{array}$ & 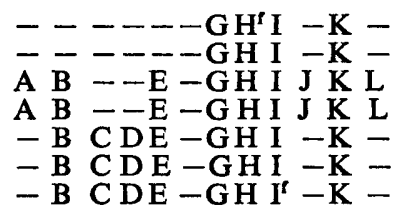 & $\begin{array}{l}1 \\
0 \\
2 \\
0 \\
0 \\
0 \\
0\end{array}$ & $\begin{array}{l}\text { N.T. } \\
\text { 6/47/53/54/75/77/83A/84/85 } \\
\text { N.T. } \\
\text { 6/53/85/+ } \\
29 \\
29 / 77 \\
29 / 52 / 52 \mathrm{~A} / 80 / 77 / 85 /+\end{array}$ \\
\hline 6 & $\begin{array}{l}8 \\
1 \\
3 \\
1 \\
1 \\
1 \\
1 \\
1 \\
1 \\
2 \\
1 \\
1 \\
1 \\
1 \\
1\end{array}$ & 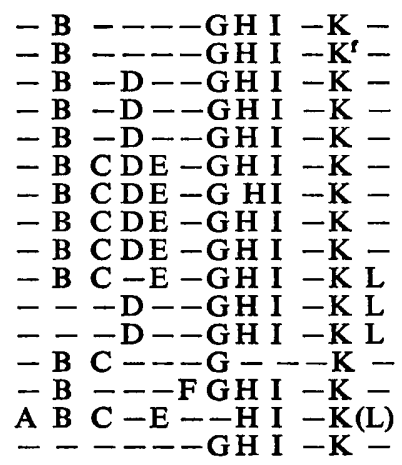 & $\begin{array}{l}0 \\
0 \\
0 \\
0 \\
0 \\
1 \\
0 \\
0 \\
0 \\
0 \\
0 \\
0 \\
0 \\
0 \\
0 \\
0\end{array}$ & $\begin{array}{l}\text { 6/47/53/54/75/83A/85/+ } \\
\text { N.T. } \\
79 \\
29 / 52 / 80 /+ \\
\text { N.T. } \\
52 /+ \\
29 / 52 \\
29 /+ \\
6 / 42 \mathrm{E} / 47 / 54 / 75 \\
55 \\
52 / 52 \mathrm{~A} / 79 / 80 / 42 \mathrm{E} \\
53 / 77 / 85 \\
29 / 52 /+ \\
\text { 52/80/42E/47/53/54/75/81/42D } \\
\text { 52/52A/80 } \\
\text { N.T. }\end{array}$ \\
\hline
\end{tabular}

* Incidents 1 and 2 occurred in the same hospital at an interval of 2 months; incident 3 was an outbreak of food poisoning.

$\dagger \ddagger \S$ See table III.

II One strain untypable on first testing.

was $-(B)-D--G H I-K L$. The strain from the cut finger of this food handler, however, was of resistotype $-(\mathrm{B})----\mathrm{GHI}-\mathrm{K}-$, and thus 
different. The strain obtained from the nose of another suspect was of resistotype $---D--G-I-K-$ and also different. These results gave exactly the same epidemiological information as did the phage-typing patterns.

Incident no. 4 occurred in a nursery, and all 11 strains were isolated from babies. On the basis of resistotyping the first four strains were apparently identical ( $-\mathrm{BCDE}-\mathrm{GHI}-\mathrm{K}-$ ) but only two of these strains had the same phage-typing pattern. Another six strains were of resistotype -B-- $\mathrm{GH}^{\mathrm{f}} \mathrm{I}-\mathrm{K}$ - and shared the same phage-typing pattern. The seventh strain was also the same resistotype but was untypable by phages.

In incident no. 5 there were several cases of wound sepsis. Four strains were of resistotype - - - - - $\mathrm{GH}^{\mathrm{f}} \mathrm{I}-\mathrm{K}-$; three of these came from wounds and the fourth from the nose of a nurse. All four were untypable by phages. A fifth strain of the same resistotype was encountered in the nose of a medical attendant, but this one had a characteristic phage-typing pattern. The next five strains were of resistotype $A B--E-G H I J K L$; these came from four cases of wound infection and a specimen of sputum; of these, four were untypable by phages. The next four strains were of resistotype $-\mathrm{BCDE}-$ $\mathrm{GHI}-\mathrm{K}-$. One of them came from a case of wound infection and the rest from members of the staff; by phage typing three were regarded as identical and the fourth as different. This would, therefore, seem to be an example of a small multifocal outbreak of sepsis.

Incident no. 6 was observed in the nursery of our hospital. Three main groups of resistotype were encountered. The first group, $-\mathrm{B}----\mathrm{GHI}-$ $\mathrm{K}-$, comprised nine strains of which the first eight came from babies and the ninth from a nurse. This latter strain was untypable by phages but by resistotyping it appeared to be identical with the rest. The second group of five strains was of resistotype $-\mathrm{B}-\mathrm{D}-\mathrm{GHI}-\mathrm{K}-$; three strains had the same phage-typing pattern and came from the same baby; the other two came from the nose of nursing attendants. These had different phage-typing patterns, but we concluded that all five were identical. The next four strains, $-\mathrm{BCDE}$ $-\mathrm{GHI}-\mathrm{K}$-, were isolated from two babies and two members of the staff. Three of them had similar phage-typing patterns and the fourth was regarded as different. On the basis of resistotyping all four strains might have been regarded as identical. Amongst the rest of the strains there were two that were identical both as regards resistotyping and phage typing: one came from a baby and the other from a patient. This is another example of a small multifocal outbreak.

\section{Discussion}

The purpose of typing staphylococci is to identify the source of infections and to follow their spread in a community. Thus reasonable proof of identity between strains is required. Whatever technical approach is employed to characterise an isolate, the basic difficulty encountered is in the genetic instability of the organism while it passes from one individual to another.

It may be that the genetic determinants for some of the markers used in the typing system can be transferred from one strain to another in the laboratory 
by transduction. The frequency of transduction is believed to be of the order of 1 in $10^{7}$ to 1 in $10^{8}$ for the transfer of a gene from a chromosomal location in the donor to a similar position in the recipient (Richmond, 1972). For plasmid markers it is probably about 100 -fold greater, but even this is not frequent enough to cause error in epidemiological studies in which only small numbers of isolates are examined. Mutation need not be considered for similar reasons. There is, however, a form of gene transfer which occurs spontaneously and at a relatively high frequency both in mixed cultures of staphylococci and on skin surfaces. This is a form of transduction that is believed to be mediated by an element composed of a defective prophage and a determinant for antibiotic resistance, which is probably on a plasmid (Lacey, 1971). The general significance of this mechanism is not yet clear.

Spontaneous plasmid loss occurs at variable frequencies, and in some instances these may be as high as 1 in 100 (Richmond, 1972). After prolonged storage on agar slopes, almost all penicillinase-producing staphylococcal cultures contain some cells that have lost the plasmid (Dyke et al., 1970). Our investigation under natural conditions of transmission suggests a loss of penicillinase plasmids in almost 1 in 10 of the cultures examined. Because loss of plasmids may lead to concomitant loss of other distinct genetic loci, any markers that happen to be associated with them have to be taken into account in epidemiological studies.

In staphylococcal phage typing the pattern of phage susceptibility depends both on the genome of the organism and on the presence or absence of temperature phages. In practice, strains of staphylococci are sufficiently stable for the technique to give valuable information in short-term investigations, but it is well known that a limited progression of lytic patterns may be encountered in long-term investigations of endemic infections. For this reason, minor changes in pattern are usually disregarded in epidemiological interpretation. Variations may also be observed in the day-to-day typing of individual strains. The techniques and limitations of phage typing of staphylococci have been extensively described by Williams and Rippon (1952), Blair and Williams (1961), Wentworth, Romig and Dixon (1964), and others.

Genetic instability also affects resistotyping. In practice the main difficulty is caused by plasmid loss. The resistotype system here described has 12 markers, four of which are known to be associated with penicillinase plasmids. Of the 301 epidemic strains of $S$. aureus investigated 27 did not form penicillinase. Of these, 22 were encountered in small groups in which the rest of the strains were homogenous in resistotype (table VII). It seemed reasonable to assume that, when a penicillinase plasmid is lost, some or all of the metal markers it carried may be simultaneously lost. In 13 strains (incidents $a-h$ ) all four metal-ion markers (AHIL) were absent, and their addition to the pattern in the penicillinase-negative strains produced the same resistotype as that of the corresponding penicillinase-positive strains. Four strains (incidents $j-m$ ) appeared to have lost resistance only to cadmium and lead ( $H$ and $I)$. In these cases the corresponding penicillinase-positive strains (the assumed parents) were sensitive to mercury (A) and arsenate (L). A single penicillinase-negative 
strain (incident $\mathrm{n}$ ) was resistant only to mercury (A); when resistances to cadmium, lead and arsenate (HIL) were added, the resulting resistotype conformed to that of the other strain of the same resistotype. Four penicillinase-negative strains had the same resistotype pattern as that of the assumed parent strains. In these cases resistance to cadmium and lead ( $\mathrm{H}$ and $\mathrm{I})$ were unaffected by the loss of penicillinase production.

\section{TABLE VII}

Loss of penicillinase production and assumed loss of plasmid-associated metal markers in 22 strains of Staphylococcus aureus

\begin{tabular}{|c|c|c|c|c|c|}
\hline $\begin{array}{l}\text { Incident } \\
\text { letter }\end{array}$ & $\begin{array}{l}\text { Number of } \\
\text { penicillinase- } \\
\text { forming } \\
\text { strains }\end{array}$ & $\begin{array}{l}\text { Resistotype of penicillinase- } \\
\text { producing strains* }\end{array}$ & $\begin{array}{l}\text { Number of } \\
\text { penicillinase- } \\
\text { negative } \\
\text { strains }\end{array}$ & $\begin{array}{l}\text { Resistotype of corresponding } \\
\text { negative strains }\end{array}$ & $\begin{array}{l}\text { Assumed } \\
\text { loss of } \\
\text { metal } \\
\text { markers }\end{array}$ \\
\hline $\begin{array}{l}\mathrm{a} \\
\mathrm{b} \\
\mathrm{c} \\
\mathrm{d} \\
\mathrm{e} \\
\mathrm{f} \\
\mathrm{g} \\
\mathrm{h} \\
\mathrm{j} \\
\mathrm{k} \\
\mathrm{l} \\
\mathrm{m} \\
\mathrm{n} \\
\mathrm{p} \\
\mathrm{q} \\
\mathrm{r}\end{array}$ & $\begin{array}{r}2 \\
3 \\
3 \\
3 \\
12 \\
12 \\
2 \\
7 \\
7 \\
8 \\
2 \\
3 \\
1 \\
1 \\
2 \\
6 \\
3\end{array}$ & 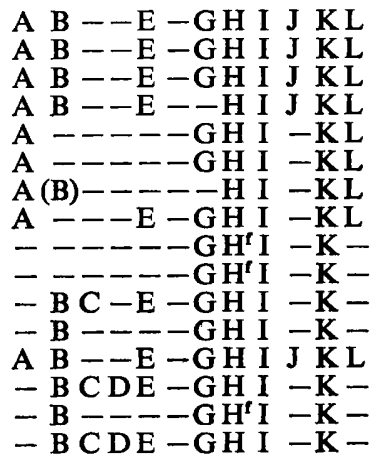 & $\begin{array}{l}1 \\
2 \\
2 \\
1 \\
2 \\
2 \\
2 \\
1 \\
1 \\
1 \\
1 \\
1 \\
1 \\
2 \\
1 \\
1\end{array}$ & 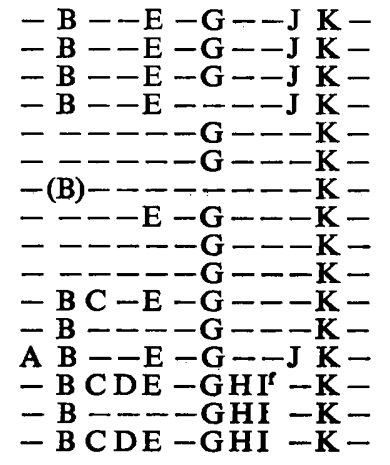 & $\begin{array}{l}\text { A H I L } \\
\text { A H I L } \\
\text { A H I L } \\
\text { A H I L } \\
\text { A H I L } \\
\text { A H I L } \\
\text { A H I L } \\
\text { A H I L } \\
\text { H I } \\
\text { H I } \\
\text { H I } \\
\text { H I } \\
\text { H I L } \\
\text { None } \\
\text { None } \\
\text { None }\end{array}$ \\
\hline
\end{tabular}

* See table II.

This instability of four of the markers is undoubtedly a disadvantage for resistotyping. Because we tested each strain for penicillinase production, however, a substitution for lost markers could be made, and this generally enabled us to identify such a strain with penicillinase-producing strains isolated in the same incident. Collateral evidence that this was a legitimate procedure was obtained in most cases; the assumption of plasmid loss with concomitant loss of metal resistances was strengthened by the finding that almost all these strains had the same phage-typing pattern as the assumed parents.

In addition to the loss of penicillinase plasmids, we also encountered other instances of variability in resistotype. Among the strains originally chosen for reference, which were subcultured serially for several years, one lost resistance to trimethylammonium bromide (E) and to cetylpyridinium chloride (J). A second strain showed a major change in resistotype and also developed an entirely different phage-typing pattern. Whilst other resistotype markers may also be associated with plasmids, our general experience with field strains suggests that they are reasonably stable.

On the whole there was satisfactory agreement between the epidemiological 
information obtained by resistotyping and the phage-typing patterns. Where resistotyping indicated that an outbreak was multifocal, the phage-typing patterns suggested the same. Conversely, when several strains within an outbreak shared the same resistotype, the phage-typing patterns were in general conformity with this.

Resistotyping may in some instances supplement or clarify the phage-typing patterns. For example, in table V, incident no. 1, there were 10 strains where the variability of the typing pattern made interpretation very difficult. Of these, seven shared the same resistotype, suggesting a common source, while the other three were different. With strains that are untypable by phages, resistotyping may in some cases provide evidence of similarity or difference. Incident no. 9 in table III represents a small outbreak of hospital sepsis in which the organism from the nose of a medical attendant proved to be of the same resistotype as five strains obtained from wound sepsis. This conclusion was later confirmed by means of experimental phages (M. T. Parker, personal communication).

When outbreaks occur in different places and at different times, the fact that the causative strains share the same phage-typing pattern is in itself not sufficient evidence of a common source. In two incidents in the same geographical area (table IV, incident no. 6 and table V, incident no. 3) 23 strains were lysed only by phage 85 ; of these 20 were the same resistotype. Strains with the same phage-typing pattern also occurred in a hospital in a neighbouring county in the same year (table IV, incident no. 7), but these had a different resistotype, suggesting that this outbreak had a different origin. The converse was also met: the same resistotype (AB--E-GHIJKL) could contain strains with different phage-typing patterns (table III, incident no. 7; table IV, incident no. 4; table V, incident nos. 2 and 4; and table VI, incident no. 5).

It would be interesting to see what correlation exists between resistotyping and serotyping of $S$. aureus. Previous studies correlating resistotyping with serotyping of $E$. coli and with colicine typing of Sh. sonnei also indicate that resistotyping will prove to be a valid technique for use with organisms for which no alternative typing method is yet available. Our findings also highlight the genetic variability of pathogenic organisms under natural conditions, which is a difficulty inherent in all typing systems.

\section{SUMMARY}

Resistotyping is based on differences in the resistance of strains of a given species to a selection of chemicals used at critical concentrations. The method was applied to Staphylococcus aureus and the patterns of response were used for epidemiological enquiry. Amongst the chemicals used were metals, and these markers showed the plasmid-associated instability already known from genetic studies. Generally the resistotypes obtained and the phage-typing patterns gave parallel information. There were examples of staphylococcal outbreaks, however, in which resistotyping amplified or clarified the findings indicated by phage-typing patterns. Conversely, in other instances phagetyping patterns subdivided a common resistotype. This investigation confirms 
the validity of resistotyping as a method of epidemiological tracing applicable to widely differing bacterial species.

We wish to express our thanks to the Endowment Fund of St George's Hospital and to the Pathological Research Fund of the Medical School for financial support. We also wish to extend our sincere thanks to Dr M. T. Parker and Dr Elisabeth H. Asheshov for providing most of the strains of staphylococci used, for the phage typing and for their generous advice in the course of this work.

\section{REFERENCES}

BARBER, M. 1949. The incidence of penicillin-sensitive variant colonies in penicillinaseproducing strains of Staphylococcus pyogenes. J. gen. Microbiol., 3, 274.

Blair, J. E. AND Williams, R. E. O. 1961. Phage typing of staphylococci. Bull. Wld Hlth Org., 24, 771.

Dyke, K. G. H., Parker, M. T. and Richmond, M. H. 1970. Penicillinase production and metal-ion resistance in Staphylococcus aureus cultures isolated from hospital patients. J. med. Microbiol., 3, 125.

EleK, S. D. AND Higney, L. 1970. Resistogram typing-a new epidemiological tool: application to Escherichia coli. J. med. Microbiol., 3, 103.

EleK, S. D., Davies, J. R. AND Miles, R. 1973. Resistotyping of Shigella sonnei. J. med. Microbiol., 6, 329.

LACEY, R. W. 1971. High frequency transfer of neomycin resistance between naturally occurring strains of Staphylococcus aureus. J. med. Microbiol., 4, 73.

Novick, R. P. AND Roth, C. 1968. Plasmid-linked resistance to inorganic salts in Staphylococcus aureus. J. Bact., 95, 1335.

Parker, M. T. 1972. Phage typing of Staphylococcus aureus. In Methods in microbiology, edited by J. R. Norris and D. W. Ribbons, vol. 7B, p. 1. London and New York.

Perret, C. J. 1954. Iodometric assay of penicillinase. Nature, Lond., 174, 1012.

Peyru, G., WeXler, L. F. AND Novick, R. P. 1969. Naturally occurring penicillinase plasmids in Staphylococcus aureus. J. Bact., 98, 215.

RichMOND, M. H. 1972. Plasmids and extra-chromosomal genetics in Staph. aureus. In The staphylococci, edited by J. O. Cohen, p. 160 and p. 162.

Richmond, M. H. AND JoHN, M. 1964. Co-transduction by a Staphylococcal phage of the genes responsible for penicillinase synthesis and resistance to mercury salts. Nature, $202,1360$.

SUBCOMMITTEE ON PHAGE-TYPING OF STAPHYLOCOCCI OF THE INTERNATIONAL COMMISSION ON Nomenclature of BaCteria. 1967. Report of meeting, Moscow, July 1966. Int. J. syst. Bact., 17, 113.

Wentworth, B. B., Romig, W. R. AND Dixon, W. J. 1964. The reproducibility of staphylococcal phage types. J. infect. Dis., 114, 179.

Williams, R. E. O. AND RipPON, J. E. 1952. Bacteriophage typing of Staphylococcus aureus. J. Hyg., Camb., 50, 320. 